\title{
Oxidation of cassava starch at different dissolved ozone concentration: effect on functional and structural properties
}

\author{
Satmalawati, E.M., *Pranoto, Y., Marseno, D.W. and Marsono, Y. \\ Department of Food and Agricultural Product Technology, Faculty of Agricultural Technology, Universitas \\ Gadjah Mada, Jalan Flora No. 1, Bulaksumur, Yogyakarta, Indonesia 55281
}

\author{
Article history: \\ Received: 6 May 2020 \\ Received in revised form: 29 \\ May 2020 \\ Accepted: 2 June 2020 \\ Available Online: 22 July \\ 2020
}

Keywords:

Cassava starch,

Oxidized starch,

Dissolved ozone,

Ozonation

DOI:

https://doi.org/10.26656/fr.2017.34(6).209

\begin{abstract}
An environmentally friendly method for starch oxidation is recommended in order to replace harmful oxidizing chemical reagents. Ozone is an environmentally friendly oxidizing reagent that leaves no residue in the final product. Studies of starch modification using dissolved ozone are still lacking. This work aimed to increase the use value and improve native starch characteristics by evaluating carbonyl and carboxyl contents, pasting and functional properties, spectral Fourier-transform infrared spectroscopy (FTIR) and X-ray diffraction (XRD) profiles, particle sizes, and scanning electron micrographs (SEM) of ozone-oxidized cassava starch. The results showed that dissolved ozone and starch slurry concentrations significantly affected oxidation degree, functional properties and caused a decrease in particle size and pasta viscosity of cassava starch. FTIR spectra significantly showed an increase in the intensity of the presence of the carbonyl group as a marker of starch oxidation. Further XRD diffraction also significantly showed changes in the relative crystallinity besides that there is a change in the surface morphology of the starch granules. Oxidized starch with a combination of $1.4 \mathrm{ppm}$ dissolved ozone concentration and a starch slurry ratio of 1:10 produced higher swelling power $(44.31 \%)$, solubility $(0.88 \%)$, lower paste viscosity $(6082.5 \mathrm{cP})$, and reconditioning relative crystallinity (10.44\%). Overall, dissolved ozone successfully had powerful effects in oxidizing starch and can be applied for starch modification as an inexpensive and safe oxidizing agent.
\end{abstract}

\section{Introduction}

Starch, which is the most abundant biopolymer used for energy reserve in most plants, consists of glucose polymers accumulated in free and independent granules (Kim et al., 2014). Starch is also a cheap and naturally renewable food source. Most starch is in the form of native starch, which has limited functional properties (Le and Angellier, 2014).

Ozonation is one of several advanced oxidation processes (AOP). When compared to other oxidizers, ozone is a strong and environmentally friendly oxidizing agent. Ozone is very easily degraded to oxygen so that it will not cause problems in the environment and leave no residue in the products produced (Çatal and Ibanoglu, 2014). The hydroxyl radical is one of the products of ozone decomposition. This radical can react via three mechanisms: (i) abstraction of hydrogen; (ii) electron transfer; and (iii) addition of Oradicals. The mechanism of ozone oxidation of starch includes the release of $\mathrm{H}$ ions, electron transfer, and reaction with ozone radicals (Vanier et al., 2017).

Ozone in dissolved phase can be more easily controlled and contact of starch particles with ozone can be more effective compared to the gas-phase ozone. Environmental and food security concerns provide an opportunity to expand the use of cassava starch, which has certain functional characteristics for meeting increasing industrial demand. This work aimed to modify cassava starch using ozone technology and also to evaluate some structural and functional properties, which can be explained in order to understand better the level of starch oxidation based on differences in dissolved ozone and starch slurry concentrations.

\section{Materials and methods}

\subsection{Materials}

Cassava (var. adira-4) with a harvest age of 10 to 11 
months was obtained in Yogyakarta, Indonesia. All chemicals used in this work were of analytical grade.

\subsection{Cassava starch preparation}

Cassava starch (also called tapioca) is made in stages that consist of stripping, dissolving, extracting, filtering, settling, and drying. To obtain the maximum starch yield $(30 \%-35 \%)$, starch extraction was done by adjusting the ratio of cassava pulp to water to $1: 4(\mathrm{w} / \mathrm{w})$. The starch sediment was dried in a cabinet drier at $50^{\circ} \mathrm{C}$ for $24 \mathrm{hrs}$ to yield a $9 \%-10 \%$ moisture level. The dried starch was ground in a mortar, sieved (60 mesh), packed in plastic packaging with silica gel wrapped in aluminium foil, put into a container, and stored at room temperature until further use.

\subsection{Ozone generator}

The corona discharge method is one of several ozone -producing methods. This method uses high voltage electricity to convert oxygen into ozone. The presence of this discharge causes excited both oxygen electrons and molecules to split into their constituent atoms, which will then be rearranged into new molecules (called ozone) consisting of three oxygen atoms in each molecule (Kim and Yousef, 1999). Corona discharge can initiate oxygen free radical formation that leads to ozone production. This corona discharge method will produce ozone at low concentrations ranging from $2.5 \%$ to $7.5 \%$, which is equivalent to 0.1 to $2 \mathrm{ppm}$ (An and Kim, 2009). This corona discharge method is widely used to make ozone generators because it is easy and cheap. An ozone generator chart is shown in Figure 1.

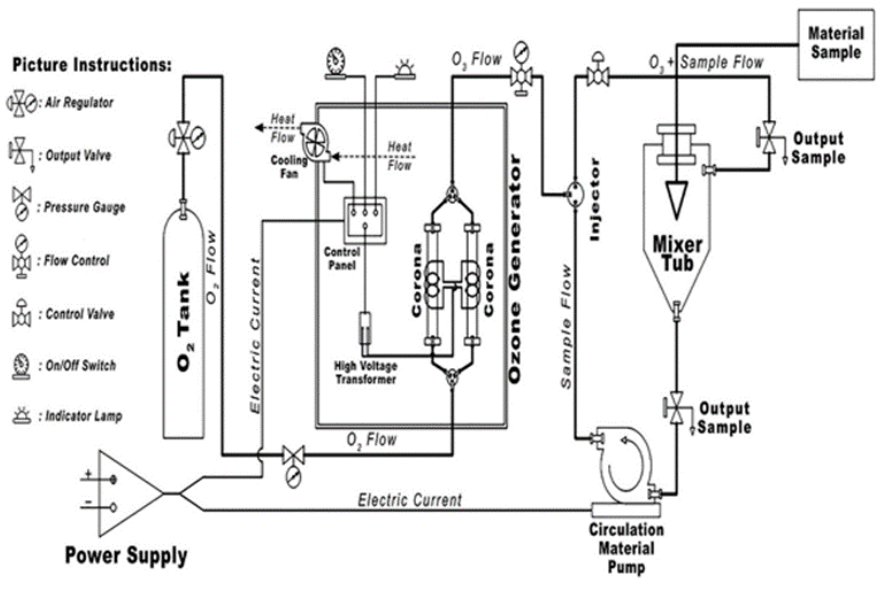

Figure 1. Ozone generator chart

\subsection{Ozonation process}

Determination of dissolved ozone concentration using the N,N-diethyl-p-phenylenediamine (DPD) indicator test kit. This DPD indicator will react with ozone to produce a pink color with a certain color intensity (Buchan et al., 2005) and converted to part per million (ppm). Dissolved ozone that was previously reacted with water to get a certain concentration. Cassava starch ozonation was performed by combining different ozone concentrations $(0,0.8,1.4,2 \mathrm{ppm})$ and starch slurry ratios of water: starch $(1: 6,1: 8,1: 10 \mathrm{w} / \mathrm{w})$. All ozonation processes were carried out for 5 mins (the half-life of ozone in pure water is more than 10 mins, but in water containing chlorine or other contaminants in small concentrations the ozone residence time is only 110 mins (Xu, 1999). Besides, based on trial, the ozonation process can't be carried out more than 5 mins due to excess foam formed during the process. The resulting starch products were precipitated out and then dried with a cabinet dryer at a temperature of $50^{\circ} \mathrm{C}$ for 24 hrs.

\subsection{Carbonyl and carboxyl contents}

The method of Smith (1967) was used to determine the carbonyl content of all samples. A starch sample (2 g) was mixed with $100 \mathrm{~mL}$ of distilled water in a $500 \mathrm{~mL}$ flask. The suspension was heated in a boiling water bath for 20 mins under constant stirring. Samples were then cooled to $40^{\circ} \mathrm{C}$, and $\mathrm{pH}$ was adjusted to 3.2 using $0.1 \mathrm{M}$ $\mathrm{HCl}$. Hydroxylamine reagent $(15 \mathrm{~mL})$ used for carbonyl measurements was then added to the mixture. The mixture was incubated in a water bath shaker at $40^{\circ} \mathrm{C}$ for $4 \mathrm{hrs}$ with slow shaking. Rapid titration with $0.1 \mathrm{M} \mathrm{HCl}$ was used to determine the excess hydroxylamine until $\mathrm{pH}$ reached to 3.2. A blank determination with only the hydroxylamine reagent was performed in the same manner. The hydroxylamine reagent was made by dissolving hydroxylamine hydrochloride $(25 \mathrm{~g})$ in $0.5 \mathrm{M}$ $\mathrm{NaOH}(100 \mathrm{~mL})$, and the volume was then adjusted to $500 \mathrm{~mL}$ with distilled water. The carbonyl content was the number of carbonyl groups per 100 glucose units $(\mathrm{CO} / 100 \mathrm{GU})$ and could be calculated with the equation (Smith, 1967):

$$
\frac{C O}{100 G U}=\frac{(V b-V s) \times M \times 0.028 \times 100}{W}
$$

In which $\mathrm{Vb}$ represents the volume of $\mathrm{HCl}$ used in the blank, Vs represents the volume of $\mathrm{HCl}$ required for the sample, $\mathrm{M}$ represents molarity of $\mathrm{HCl}$, and $\mathrm{W}$ represents the sample mass in dry weight $(\mathrm{g})$.

The method for determining carboxyl content of all samples has previously been described by Chattopadhyay et al. (1997). Starch (2 g) was mixed with $25 \mathrm{~mL}$ of $0.1 \mathrm{M} \mathrm{HCl}$, and the mixture was incubated for 30 mins under constant stirring. The mixture was then vacuum-filtered through filter paper, and distilled water was used to wash the chlorine residue within the sample. The resulting starch was suspended in distilled water $(300 \mathrm{~mL})$ and gelatinized in a water bath for 15 min with constant stirring. The sample was then 
immediately titrated with $0.1 \mathrm{M} \mathrm{NaOH}$ until the $\mathrm{pH}$ reached 8.3. A native sample was used as a blank and subject to similar treatment. The result was the number of carboxyl groups per 100 glucose units $(\mathrm{COOH} / 100 \mathrm{GU})$ that could be calculated with the equation (Chattopadhyay et al., 1997):

$$
\frac{C O}{100 G U}=\frac{(V b-V s) \times M \times 0.045 \times 100}{W}
$$

In which Vs represents the volume of $\mathrm{NaOH}$ required for the sample $(\mathrm{mL}), \mathrm{Vb}$ represents the volume of $\mathrm{NaOH}$ used to test the blank (mL), M represents the molarity of $\mathrm{NaOH}$, and $\mathrm{W}$ represents the sample mass on a dry weight basis.

\subsection{Swelling power and solubility}

Sample swelling power was determined based on a previously described method (Adebowale et al., 2002). A starch sample $(1.0 \mathrm{~g})$ was weighed and placed into a clear dried test tube, which had been weighed first. The sample and tube weight were calculated together as W1. Distilled water $(50 \mathrm{~mL})$ was added to the sample until a slurry formed. The mixture was then homogenized and heated at $95^{\circ} \mathrm{C}$ for 30 mins in a water bath. The mixture was cooled until the temperature was reached to $30 \pm 2^{\circ} \mathrm{C}$ and centrifuged (15 mins) until the gel and aliquots were separated. Aliquots $(5 \mathrm{~mL})$ were dried at $110^{\circ} \mathrm{C}$ until a constant weight was reached. The residue obtained after drying the supernatant could be expressed as the amount of starch solubilized in water. Solubility was calculated as $\mathrm{g}$ per $100 \mathrm{~g}$ of starch on a dry weight basis. The gel and test tube from the above experiment (after centrifugation) with its retained water were quantitatively weighed and taken together as W2. The swelling power was calculated with the equation:

Swelling power $(\%)=\mathrm{W} 2-\mathrm{W} 1 /$ weight of starch (dry weight basis)

\subsection{FT-IR spectroscopy analysis}

The infrared spectra of the native and ozoneoxidized cassava starches in the region of $4000-400 \mathrm{~cm}^{-1}$ were obtained with Thermo Scientific (Nicolet iS-10, Madison USA). Dried starch samples (without $\mathrm{KBr}$ ) were directly placed on the diamond sensor of the instrument. Three readings were collected at a resolution of $4 \mathrm{~cm}^{-1}$ (Monroy et al., 2018). All spectra were analyzed using Thermo Fisher Scientific Omnic analysis software and Origin 2016.

\subsection{X-ray diffraction and relative crystallinity}

X-ray identification was carried out with an X-ray diffractometer (Rigaku Miniflex 600 RXD, Tokyo, Japan). The operation angle was 3 to $45^{\circ}$ for $2 \theta$ using the working conditions:(1) scan rate of $2^{\circ} \mathrm{min}^{-1}$ and (2) $40 \mathrm{kV}$ and $15 \mathrm{~mA}$. Several methods were used to calculate the relative crystallinity $(\mathrm{RC})$ of the starch granules using the Origin software 2016 for graphing and analysis (Nara et al., 1978; Srichuwong et al.,2005; Rocha et al., 2008; Katsumi et al., 2015).

\subsection{Scanning electron microscopy}

The appearance of a granular surface was determined using a scanning electron microscope (SEM JEOL-JSM6510, JEOL Ltd.Tokyo Japan). The starch sample was placed in a single layer position on carbon type. A sample was then coated using platinum and examined under an SEM set at a wide distance (WD) of $11 \mathrm{~mm}$, spot size (SS) of 40 and voltage of $15 \mathrm{kV}$.

\subsection{Pasting properties}

A Rapid Visco Analyser (Newport Scientific; Warriewood NSW, Australia) was used to determine starch pasting properties with a Standard Analysis 1 profile, and the result was expressed in $\mathrm{cP}$ (centiPoise) with pasting temperature, peak viscosity, breakdown, final viscosity, and setback as parameters. The sample was weighed directly into the aluminium RVA canister, and $25 \mathrm{~mL}$ of distilled water was then added to the canister. The temperature of the sample was held at $50^{\circ} \mathrm{C}$ for $1 \mathrm{~min}$, increased to $95^{\circ} \mathrm{C}$ in $3.7 \mathrm{mins}$, and then held at $95^{\circ} \mathrm{C}$ for 2.5 mins. The temperature of the sample was then decreased to $50^{\circ} \mathrm{C}$ in $3.8 \mathrm{~min}$ and then held at $50^{\circ} \mathrm{C}$ for 2 mins. The rotating speed was held at $960 \mathrm{rpm}$ for 10 second $160 \mathrm{rpm}$ for the remainder of the process. All parameters were then recorded (Gozé et al., 2016).

\subsection{Particle size}

Particle sizes of all samples were determined using Laser Scattering Particle Size (Horiba LA-960, Japan) according to the method by Torres et al. (2014) with slight modification. A sample was placed in a cuvette, and water was added as a dispersion media. Purified water should always be used to ensure that it was particle free. The starch slurry was injected at transmittance index of $80 \%$ to $90 \%$. Circulation using laser and peak recording was done using a photomultiplier tube (PMT) detector. The recording time was $120 \mathrm{~s}$.

\subsection{Statistical analysis}

Data were analyzed using Statistical Product and Service Solution (SPSS) version 17 with the variance analysis method (ANOVA), then followed by Duncan Test to detect differences. Significance was confirmed at $P$ values $<0.05$. 


\section{Results and discussion}

\subsection{Carbonyl and carboxyl content}

Starch molecules are rich in hydroxyl groups (C$\mathrm{OH})$. As pointed out earlier, the substitution of these groups by carbonyl $(\mathrm{C}=\mathrm{O})$ and carboxyl $(\mathrm{HO}-\mathrm{C}=\mathrm{O})$ groups is expected during the oxidation process, and the higher value of these new groups, the higher degree of substitution due to oxidation. In this study, it was observed that the more dilute the starch slurry was, the higher the carbonyl and carboxyl levels were as shown in Figure 2. The assumption is, the more dilute the slurry concentration, the more effective ozone contact with starch particles becomes in the oxidation process. While ozone concentration also affects carbonyl and carboxyl levels, at certain concentrations, a decrease in the degree of oxidation occurs.
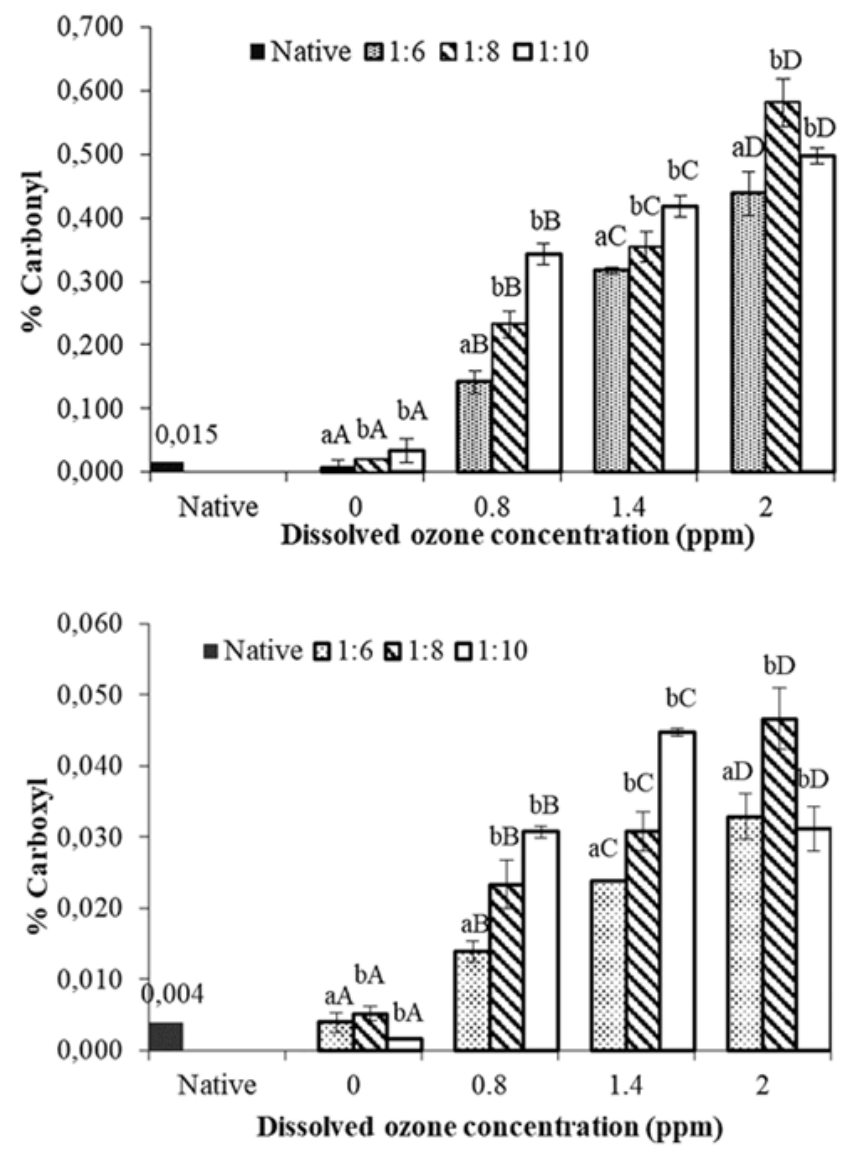

Figure 2. Carbonyl/carboxyl content of native and ozoneoxidized starch. The same letter notation indicated no significant difference at the $5 \%$ probability level. a,b,c: indicates slurry concentration; A,B,C: indicates dissolved ozone concentration

Three reactions occur concurrently during oxidation: (i) oxidation accompanied by the formation of carbonyl and carboxyl groups; (ii) further oxidation transformation of carbonyl to the carboxyl group; and (iii) decarboxylation. During the next stage of the reaction, it is also possible that some oxidized starch became highly degraded and therefore, dissolved in water (El-sheikh et al., 2010). As in this study, oxidation using 2 ppm dissolved ozone with the most dilute starch slurry concentration caused a reduction in carbonyl and carboxyl levels.

\subsection{Swelling power and solubility}

Swelling powers and solubilities of native and ozone -oxidized starches are shown in Figure 3. Swelling power results for all treatments were greater than native starch. The combined treatment of a starch slurry ratio1:10 with a $1.4 \mathrm{ppm}$ ozone concentration produced the largest swelling power $(44.30 \%)$. The slurry concentration had a significant effect on swelling power, the more dilute the starch slurry, the larger the swelling power.
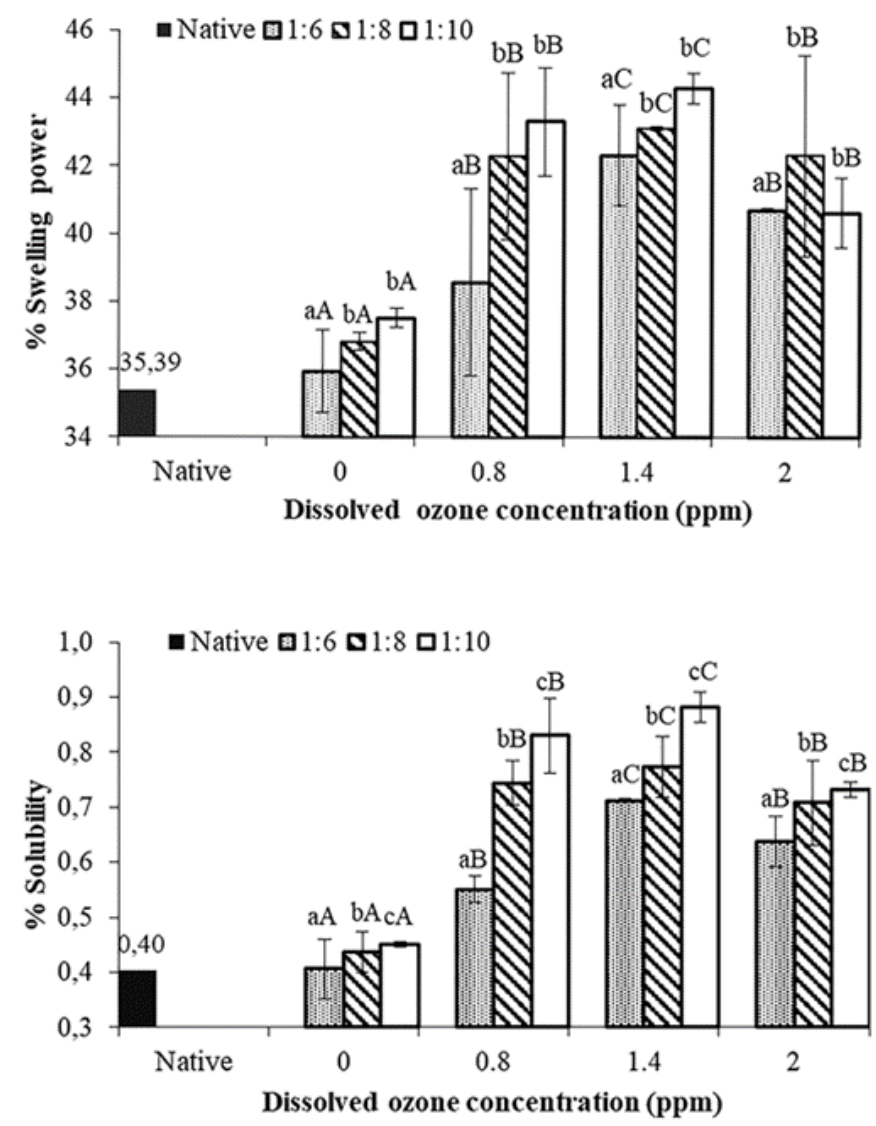

Figure 3. Swelling power and solubility of ozone-oxidized starch. The same letter notation indicated no significant difference at the $5 \%$ probability level. a,b,c: indicates slurry concentration; A,B,C: indicates dissolved ozone concentration.

The difference in swelling power was related to the speed of depolymerization of starch polymers to form carbonyl groups of which further oxidation leads to the formation of the carboxyl group in the ozone-oxidation process. The increase in swelling power of starch oxidation could be due to the presence of a hydrophilic carboxyl group and the presence of a repulsive force between negative charges. 
Solubility represents the amount of solubilized starch molecules at a certain temperature (Wang and Wang, 2003). The solubilities and swelling powers of ozoneoxidized starches were greater than native starches. The increase in solubility could be related to the depolymerization and structural weakening of starch granule due to oxidation process (Adebowale et al., 2002). The lower solubility at $2.0 \mathrm{ppm}$ could be related to the presence of cross-linking that prevented amylopectin molecules from leaching out in addition to inefficient oxidation process shown by lower carboxyl and carbonyl contents at a starch slurry ratio of 1:10. Abundant free radicals that form can mutually destroy themselves by coupling, and the oxidation process would then not proceed as efficiently (Wang and Wang, 2003; El-sheikh et al., 2010)

\subsection{FTIR spectroscopy analysis}

Native starch has major chemical group parts at main clusters of $\mathrm{C}-\mathrm{H}, \mathrm{C}=\mathrm{C}, \mathrm{O}-\mathrm{H}$, and $\mathrm{C}-\mathrm{O}$. The absorbance at $3300-2500 \mathrm{~cm}^{-1}$ could be attributed to $\mathrm{O}-\mathrm{H}$ bond stretching. The absorbance at 2932; 927 and $859 \mathrm{~cm}^{-}$ ${ }^{1}$ were designated as $\mathrm{C}-\mathrm{H}$ stretching and bending, respectively, $\mathrm{C}=\mathrm{C}$ appeared at1643 $\mathrm{cm}^{-1}$, and $\mathrm{C}-\mathrm{O}$ stretching appeared at $1077 \mathrm{~cm}^{-1}$. The of the Fouriertransform infrared (FTIR) spectra of ozone-oxidized cassava starch are shown in Figure 4.

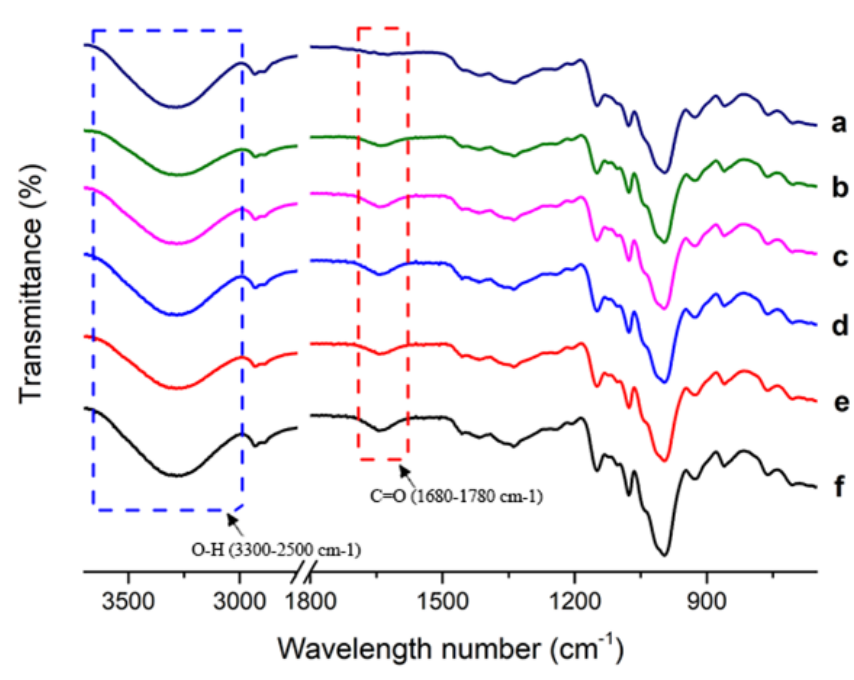

Figure 4. Fourier-transform infrared (FTIR) spectra of native and dissolved ozone-oxidized starch: (a) native starch;(b) 1:6, $0.8 \mathrm{ppm}$; (c) 1:8, $0.8 \mathrm{ppm}$; (d) 1:8, 2 ppm; (e) 1:10, $1.4 \mathrm{ppm}$; (f) $1: 10,2 \mathrm{ppm}$

In low dissolved ozone concentrations, the starch oxidation reaction did not occur in a proper manner. This improper functioning was indicated by the absence of anew peak at about $1700 \mathrm{~cm}^{-1}$, which is generally assigned as a carbonyl group $(\mathrm{C}=\mathrm{O})$ (Lisie et al., 2015). Previous studies have reported that the starch slurry concentration had a significant effect on starch oxidation, primarily in carbonyl group formation as the main product during starch oxidation. It appeared that the Fourier-transform infrared (FT-IR) spectra were different at the same dissolved ozone concentration $(0.8 \mathrm{ppm})$ with starch slurry ratios of 1:6 and 1:8.

Transmittance indicating carbonyl $(\mathrm{C}=\mathrm{O})$ groups could be observed at a starch slurry of $1: 8$, which is identified by stretching modes in the 1703 and $1748 \mathrm{~cm}^{-1}$ regions. Carbonyl groups generally appear at 1680 to $1780 \mathrm{~cm}^{-1}$ (Petit and Puskar, 2018). There was an increase in the intensity of the carbonyl content at high ozone concentrations and dilute starch slurries. Generally, the $\mathrm{C}=\mathrm{O}$ stretching band shifts toward higher frequencies as the level of oxidation increases.

Modification of cassava starch at starch slurry ratios of 1:8 and 1:0 indicates carbonyl groups that can be seen at $1748 \mathrm{~cm}^{-1}$ as a result of ozone oxidation. Higher slurry concentrations would increase the effectiveness of the oxidation process. The results showed a difference in peak sharpness $\left(1680-1780 \mathrm{~cm}^{-1}\right)$ which is a marker of carbonyl groups, as well as an increase in hydroxyl groups $\left(3300-2500 \mathrm{~cm}^{-1}\right)$. Starch oxidation is more effective at dilute slurry concentrations. It is suspected that starch particle contact with ozone is simultaneous, so it can produce carbonyl-carboxyl groups in oxidation reactions.

\section{$3.4 X$-ray diffraction and relative crystallinity}

The degree of crystallinity of native starch granules ranges from $15 \%$ to $45 \%$, and the average degree of the amorphous region was $70 \%$; furthermore, it could be classified into three types, namely $\mathrm{A}, \mathrm{B}$, and $\mathrm{C}$ (Cheetham and Tao, 1998). Relative crystallinity (RC) was directly related to the amylopectin content and chain length, and inversely proportional to the amylose content (Hoover, 2001).

Ozone-oxidized starch had a lower degree of crystallinity compared to native starch $(24.74 \%)$. The Xray diffraction patterns and $\mathrm{RC}$ values of the native and the ozone-oxidized cassava starches are presented in Figure 5.

The concentration of starch slurry and dissolved ozone concentration affected paste viscosity. This finding could be related to the depolymerization of the starch molecular chain. Oxidation of starch granules could also be demonstrated by hydrolysis of the glycosidic linkages. Ozone-oxidized starch at a 1:10 slurry concentration with $1.4 \mathrm{ppm}$ dissolved ozone had the lowest RC value (10.44\%). Lower RC values of ozone-oxidized compared to native starches showed that oxidation occurred not only in the amorphous lamellae but also in the semi-crystalline domains of the starches. 
Thus, the decrease in ozone-oxidized cassava starch RC in aqueous solution at different slurry and dissolved ozone concentrations is probably a result of amylopectin chain depolymerization as a result of $\alpha$ - $(1,4)$-glucosidic linkage cleavage. RC decrease after ozone-oxidation of cassava starch in aqueous solution demonstrated that semi-crystalline domains of starches were affected by ozone-oxidation (Klein et al., 2013).

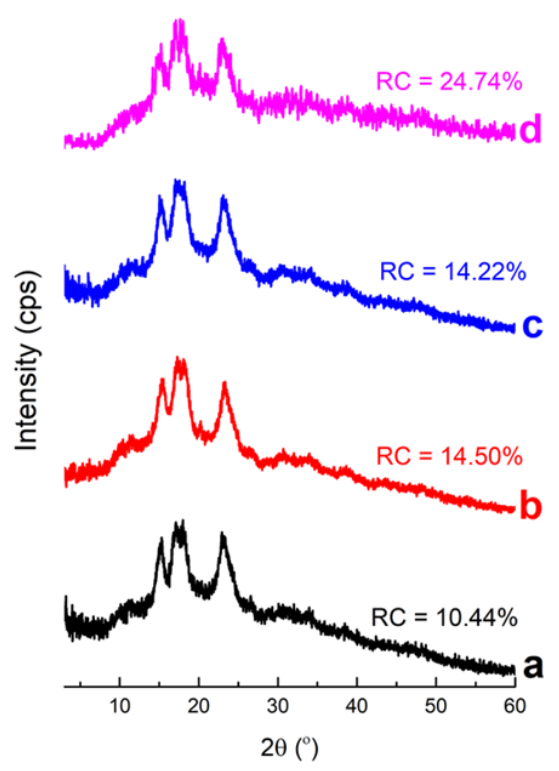

Figure 5. X-ray diffraction of native and ozone-oxidized starch at different starch slurry-dissolved ozone concentrations: a (1:10, $1.4 \mathrm{ppm}), \mathrm{b}(1: 8,2 \mathrm{ppm}), \mathrm{c}(1: 6,0.8$ ppm), d (native)

\subsection{Scanning electron micrographs}

SEM yielded information about the appearance of granular surfaces and was applied to evaluate whether the ozone treatment in aqueous solution at different starch slurry concentrations affects the morphology of the starch granules (Figure 6).

Starch granules have an oval to round shape with a smooth surface. Similar to other studies, the granular surface of native starch was smooth and relatively free from imperfections as normally observed in native starch granules (Klein et al., 2014; Castanha et al., 2017; Perez and Agama, 2017). In contrast, ozone-oxidation starch granule morphology showed rough surfaces and porous shapes. Ozone-oxidation caused production of irregular starch granules. This can be explained that the starch particles cracked as oxidant concentration increased due to the starch crystalline structure weakening (Castanha et al., 2017). An ozone concentration of $0.8 \mathrm{ppm}$ in starch slurry demonstrated a morphological change in starch granule surfaces. Irregular shapes were increasingly observed as dissolved ozone concentrations increased. This finding is consistent with the results of functional properties, such as swelling rates and solubility, which were greater in more porous starch granules. In this study, the functional properties of ozonation starch decreased at ozone concentration of $2 \mathrm{ppm}$ (discussed in the previous section). SEM results showed the surface of starch granules eroded more clearly at ozone

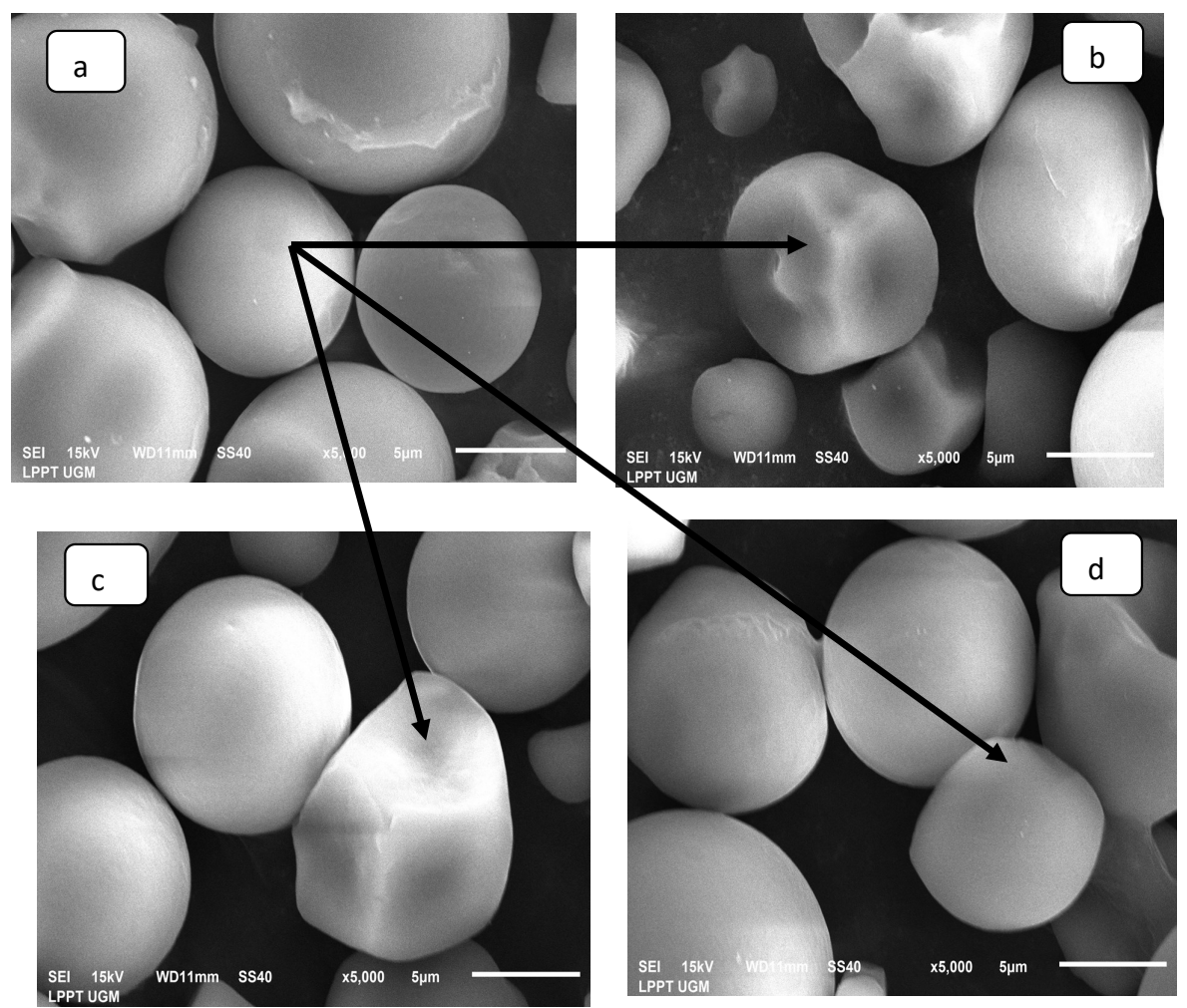

Figure 6. Scanning electron microscopy (SEM) of ozone-oxidized starcha: native; b: 0.8 ppm dissolved ozone at starch slurry ratio 1:6; c: 1.4 ppm dissolved ozone at starch slurry ratio 1:10; and d: 2 ppm dissolved ozone at a starch slurry ratio 1:8 
concentrations of $0.8 \mathrm{ppm}$ and $1.4 \mathrm{ppm}$ compared to 2 ppm).

\subsection{Paste viscosity}

According to the data in Figure 7, peak viscosity decreased as dissolved ozone concentration increased. This finding is also supported by starch slurry dilution, which indicates that under stirring and heating, modified starch granules presented the poor capacity for maintaining their as they were ruptured in a shorter time than native starch.

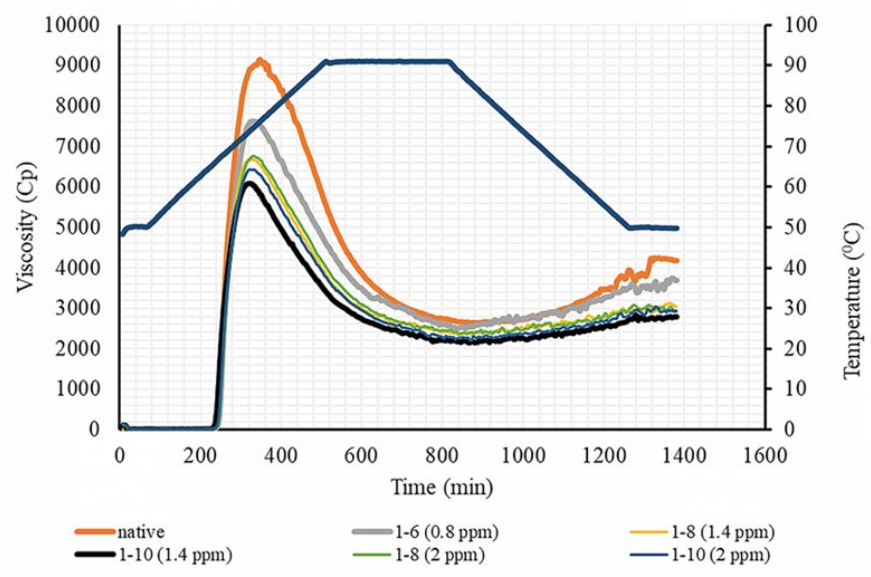

Figure 7. Paste viscosity of native and ozone-oxidized starch

The lower number of hydrogen bonds could be related to the decrease in hydroxyl groups within the granule due to carbonyl and carboxyl group formation. Hydrogen bonds have an essential role in maintaining the integrity of starch granules, so that integrity became so poor due to the decrease of hydrogen bonds amount. Carbonyl and carboxyl group formation during oxidation could also be suggested as the cause for the weakening of the starch granule (Castanha et al., 2017). Previous studies have reported that the decrease in viscosity occurred in conjunction with an increase in oxidation time and ozone concentration (Oladebeye et al., 2013; Çatal and Ibanoglu, 2014; Klein et al., 2014).

According to the data, it can be concluded that ozone -oxidized starches were most likely to present poor granular structures. This finding can be related to the electronegative charges of carbonyl and carboxyl groups within the molecule. Furthermore, lower resistance of shear forces was established due to partial cleavage of the glycosidic bonds that led to molecular and network degradation. Dissolved ozone concentration at $2.0 \mathrm{ppm}$ tends to increase peak viscosity (Castanha et al., 2017). It has been reported that the paste viscosity possibly increased because of cross-linking effects and an increase in carboxylic groups, which are responsible for preventing molecular association and allowing the granules to undergo water uptake.

\subsection{Particle size}

The particle size of native starch was mainly distributed at $17.38 \mu \mathrm{m}(81 \%)$. The granules exhibited wide variations in the sizes ranging from 5 to $40 \mathrm{um}$, and variations in granular size distribution among varieties and during growth periods were documented. The sizes ranging from 7 to $20 \mu \mathrm{m}$ occurred most frequently (Rolland-sabaté et al., 2012). The average size of granules from normal genotypes differed greatly between different studies (10-18 um) (Arachchige et al., 2009; Waterschoot et al., 2016).

Apparently, ozone oxidation had an effect on the size reduction of the starch granule size. The oxidized starches with $1: 6 ; 1: 8$, and $1: 10$ starch slurry and 0.8 and $2.0 \mathrm{ppm}$ ozone concentrations were capable of converting starch particles into smaller sizes. Ozone oxidation was capable of successfully causing degradation in particle size $(17.38 \mu \mathrm{m})$ of native starch from $81.8 \%$ to $10.9 \%-11.6 \%$. The particle size distribution of native and ozone-oxidized starches is shown in Figure 8.

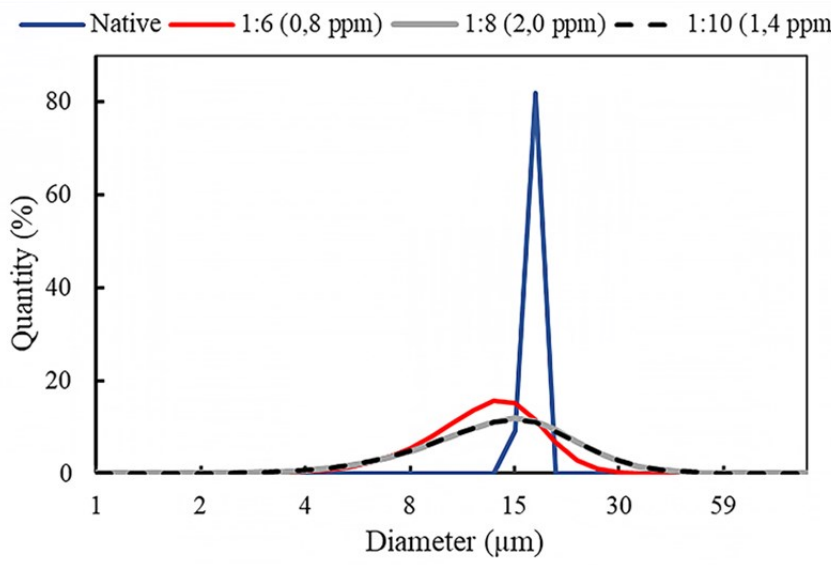

Figure 8. Starch particle size of native and ozone-oxidized starch

The granule size of native starch was mainly found at 15 to $17 \mu \mathrm{m}$, while ozone-oxidized starches were distributed from 2.6 to $17 \mu \mathrm{m}$. The concentration of starch slurry and dissolved ozone significantly took effect on the degradation of granule size. The granule size of ozone-oxidized starch with 1:6 slurry concentration and $0.8 \mathrm{ppm}$ ozone were $12 \mu \mathrm{m}$, whereas, at 1:8 and 1:10 slurry concentrations, a percentage of granule size $(12 \mu \mathrm{m})$ had degraded into smaller ones. Oxidation of starch granules resulted in surface erosion with notch and groove formation and some holes appeared in the starch granules after oxidation (Kuakpetoon and Wang, 2008). Another opinion states that starch oxidation is a preliminary treatment in the manufacture of starch nanoparticles, with the mechanism of surface erosion of starch granules so that the size of the granules is degraded (Sun et al., 2014). 


\section{Conclusion}

Dissolved ozone caused successful oxidation of cassava starch. Different ozone and starch slurry ratios significantly affected functional and structural properties of modified cassava starches, thus resulting in higher swelling powers, solubilities and lower peak viscosities than native starch. Ozone-oxidized starch ozonation also caused a decrease in starch crystallinity and degradation of granular particle size. Data variation in several studies occurred due to differences in selected ozonation methods and starch sources. Ozone-oxidation differs from common oxidation processes in that oxidation with ozone produced more carbonyl groups than carboxyl groups.

\section{Acknowledgements}

The research work was funded by Directorate of Research and Comunity Service, Ministry of Research Technology and Higher Education.

\section{References}

Adebowale, K.O., Afolabi, A.T. and Lawal, O.S. (2002). Isolation, chemical modification and physicochemical characterisation of Bambarra groundnut (Voandzeia subterranean) starch and flour. Food Chemistry, 78(3), 305-311. https:// doi.org/10.1016/S0308-8146(02)00100-0

An, H.J. and Kim, J.M. (2009). Using Ozonation and Amino Acids to Change Pasting Properties of Rice Starch. Journal of Food Science, 74(3), 278-283. https://doi.org/10.1111/j.1750-3841.2009.01109.x

Arachchige, H., Wickramasinghe, M., Takigawa, S., Matsuura-Endo, C., Yamauchi, H. and Noda, T. (2009). Comparative analysis of starch properties of different root and tuber crops of Sri Lanka. Food Chemistry, 112(1), 98-103. https://doi.org/10.1016/ j.foodchem.2008.05.046

Buchan, K.A.H., Martin-robichaud, D.J. and Benfey, T.J. (2005). Measurement of dissolved ozone in seawater: A comparison of methods. Aquacultural Engineering, 33(3), 225-231. https:// doi.org/10.1016/j.aquaeng.2005.02.002

Castanha, N., Matta Junior, M.D.D. and Augusto, P.E.D. (2017). Potato starch modification using the ozone technology. Food Hydrocolloids, 66, 343-356. https://doi.org/10.1016/j.foodhyd.2016.12.001

Çatal, H. and Ibanoglu, S. (2014). Effect of aqueous ozonation on the pasting, flow and gelatinization properties of wheat starch. Food Science and Technology, 59(1), 577-582. https://doi.org/10.1016/ j.lwt.2014.04.025

Chattopadhyay, S., Singhal, R.S. and Kulkarni, P.R.
(1997). Optimisation of conditions of synthesis of oxidised starch from corn and amaranth for use in film-forming applications. Carbohydrate Polymers, 34(4), 203-212. https://doi.org/10.1016/S0144-8617 (97) $87306-7$

El-sheikh, M.A., Ramadan, M.A. and El-shafie, A. (2010). Photo-oxidation of rice starch . Part I : Using hydrogen peroxide. Carbohydrate Polymers, 80(1), 266-269. https://doi.org/10.1016/ j.carbpol.2009.11.023

Fouladi, E. and Nafchi, A.M. (2014). Effects of acidhydrolysis and hydroxypropylation on functional properties of sago starch. International Journal of Biological Macromolecules, 68, 251-257. https:// doi.org/10.1016/j.ijbiomac.2014.05.013

Gozé, P., Rhazi, L., Pauss, A. and Aussenac, T. (2016). Starch characterization after ozone treatment of wheat grains. Journal of Cereal Science, 70, 207213. https://doi.org/10.1016/j.jcs.2016.06.007

Hoover, R. (2001). Composition, molecular structure, and physicochemical properties of tuber and root starches: a review. Carbohydrate Polymers, 45(3), 253-267. https://doi.org/10.1016/S0144-8617(00) 00260-5

Katsumi, N., Okazaki, M., Yonebayashi, K. and Kawashima, F. (2015). New Proposal for “ Crystalline Index ” of Starch. Sago Palm, 22, 25-30.

Kaur, B., Ariffin, F., Bhat, R. and Karim, A.A. (2012). Progress In Starch Modification in the Last Decade. Food Hydrocolloids, 26(2), 398-404. https:// doi.org/10.1016/j.foodhyd.2011.02.016

Kim, H.-Y., Park, S.S. and Lim, S.-T. (2014). Preparation, characterization and utilization of starch nanoparticles. Colloids and Surfaces B: Biointerfaces, 126, 602-620. https://doi.org/10.1016/ j.colsurfb.2014.11.011

Kim, J. and Yousef, A.E. (1999). Application of Ozone for Enhancing the Microbiological Safety and Quality of Foods: A Review. Journal of food Protection, 62(9), 1071-1087. https:// doi.org/10.4315/0362-028X-62.9.1071

Klein, B., Levien, N., Moomand, K., Zanella, V., Colussi, R., Zavareze, R. and Dias, A.R.G. (2014). Ozone oxidation of cassava starch in aqueous solution at different pH. Food Chemistry, 155, 167173. https://doi.org/10.1016/j.foodchem.2014.01.058

Klein, B., Zanella, V., Levien, N., Zavareze, R., Colussi, R., Amaral, J., Gutkoski, L.C. and Dias, A.R.G. (2013). Effect of single and dual heat - moisture treatments on properties of rice, cassava, and pinhao starches. Carbohydrate Polymers, 98(2), 1578-1584. https://doi.org/10.1016/j.carbpol.2013.07.036 
Kuakpetoon, D. and Wang, Y. (2008). Locations of hypochlorite oxidation in corn starches varying in amylose content. Carbohydrate Research, 343(1), 90 -100. https://doi.org/10.1016/j.carres.2007.10.002

Le, D. and Angellier-coussy, H. (2014). Preparation and application of starch nanoparticles for nanocomposites : A review. Reactive and Functional Polymers, 85, 97-120. https://doi.org/10.1016/ j.reactfunctpolym.2014.09.020

Lisie, S., El, M., Colussi, R., Zanella, V., Bartz, J., Radunz, M., Carreno, N.L.V., Dias, A.R.G. and Zavareze, R. (2015). Structure, morphology and functionality of acetylated and oxidised barley starches. Food Chemistry, 168, 247-256. https:// doi.org/10.1016/j.foodchem.2014.07.046

Monroy, Y., Rivero, S. and García, M.A. (2018). Ultrasonics - Sonochemistry Microstructural and techno-functional properties of cassava starch modified by ultrasound. Ultrasonics Sonochemistry, 42, 795-804. https://doi.org/10.1016/ j.ultsonch.2017.12.048

Nara, B.S., Mori, A. and Komiya, T. (1978). Study on Relative Crystallinity of Moist Potato Starch. Starke Starch, 30(4), 111-114. https://doi.org/10.1002/ star. 19780300403

Oladebeye, A.O., Oshodi, A.A., Amoo, I.A. and Karim, A.A. (2013). Functional, thermal and molecular behaviours of ozone-oxidised cocoyam and yam starches. Food Chemistry, 141(2), 1416-1423. https://doi.org/10.1016/j.foodchem.2013.04.080

Perez, L.A.B. and Agama-acevedo, E. (2017). Starch. In Villar, M.A., Barbosa, S.E., Garcia, A.M., Castillo, L.A. and Lopez, O.V. (Eds.) Starch-Based Materials in Food Packaging. USA: Academic Press. https:// doi.org/10.1016/B978-0-12-809439-6.00001-7

Petit, T. and Puskar, L. (2018). Diamond and Related Materials FTIR spectroscopy of nanodiamonds: Methods and interpretation. Diamond and Related Materials Journal, 89, 52-66. https:// doi.org/10.1016/j.diamond.2018.08.005

Rocha, S., Demiate, I.M. and Franco, M.L. (2008). Características estruturais e físico-químicas de amidos de mandioquinha-salsa (Arracacia xanthorrhiza) Structural and physicochemical characteristics of Peruvian carrot (Arracacia xanthorrhiza) starch. Ciência e Tecnologia de Alimentos, Campinas, 28(3), 620-628. https:// doi.org/10.1590/S0101-20612008000300018

Rolland-sabaté, A., Sánchez, T., Buléon, A., Colonna, P., Jaillais, B., Ceballos, H. and Dufour, D. (2012). Food Hydrocolloids Structural characterization of novel cassava starches with low and high-amylose contents in comparison with other commercial sources. Food Hydrocolloids, 27(1), 161-174. https://doi.org/10.1016/j.foodhyd.2011.07.008

Smith, R.J. (1967). Characterization and analysis of starches. In Whistler, R.L. and Paschall, E.F. (Eds.). Starch Chemistry and Technology, Vol. 2. USA: Academic Press.

Srichuwong, S., Isono, N., Mishima, T. and Hisamatsu, M. (2005). Structure of lintnerized starch is related to X-ray diffraction pattern and susceptibility to acid and enzyme hydrolysis of starch granules. International Journal of Biological Macromolecules, 37(3), 115-121. https://doi.org/10.1016/ j.ijbiomac.2005.09.006

Sun, Q., Fan, H. and Xiong, L. (2014). Preparation and characterization of starch nanoparticles through ultrasonic-assisted oxidation methods. Carbohydrate Polymers, 106, 359-364. https://doi.org/10.1016/ j.carbpol.2014.02.067

Torres, M.D., Moreira, R., Chenlo, F., Morel, M.H. and Barron, C. (2014). Physicochemical and Structural Properties of Starch Isolated from Fresh and Dried Chestnuts and Chestnut Flour. Properties of Chestnut Starch, Food Technology and Biotechnology, 52(1), 135-139.

Vanier, N.L., Lisie, S., El, M., Renato, A., Dias, G. and Zavareze, R. (2017). Molecular structure, functionality and applications of oxidized starches: A review. Food Chemistry, 221, 1546-1559. https:// doi.org/10.1016/j.foodchem.2016.10.138

Wang, Y.J. and Wang, L. (2003). Physicochemical Properties of Common and Waxy Corn Starches Oxidized by Different Level of Sodium Hypochlorite. Carbohydrate Polymers, 52(3), 207217. https://doi.org/10.1016/S0144-8617(02)00304-1

Waterschoot, J., Gomand, S.V. and Delcour, J.A. (2016). Food Hydrocolloids Impact of swelling power and granule size on pasting of blends of potato, waxy rice and maize starches. Food Hydrocolloids, 52, 69 -77. https://doi.org/10.1016/j.foodhyd.2015.06.012

$\mathrm{Xu}, \mathrm{L}$. (1999). Use of Ozone to Improve the Safey of Fresh Fruits and Vegetables. Food Technology, 53, 58-62. 